\title{
ISB News
}

\author{
(C) ISB 2010
}

ISB News May 2010

From the President

The ISB Secretary, Prof. Mark D. Schwartz, attended the first meeting of the International Forum of Meteorological Societies (IFMS) on behalf of ISB, which was held 19-20 January 2010 in Atlanta, Georgia, USA (IFMS Global Meeting One, GM-1). The fundamental goal of the IFMS, as stated on its web site, is "to foster and encourage communication and exchange of knowledge, ideas and resources among the world's more than sixty meteorological societies" (IFMS 2010). Further, the IFMS will focus on advancing the goals and objectives of the world's professional and scientific meteorological societies (IFMS 2010). IFMS appears to be a valuable forum in support of interactions and joint actions that are of interest and relevance to ISB. Thus, at the meeting, Prof. Schwartz formally committed ISB as a member of IFMS, and also personally agreed to work with a sub-committee that will advise on content issues for the IFMS web page (http:// www.ifms.org/), which will be technically supported by American Meteorological Society staff. The web site currently includes further information about the IFMS and its first meeting, including the IFMS Terms of Reference, and the IFMS Charter. Prof. Schwartz's attendance at the meeting was fully funded by the Tromp Travel Fund.

Paul J. Beggs

ISB President

Environmental Science

Department of Environment and Geography

Macquarie University

paul.beggs@mq.edu.au

\section{Reference}

IFMS (2010) Welcome to the International Forum of Meteorological Societies. International Forum of Meteorological Societies. http:// www.ifms.org/. Accessed 11 March 2010 